\title{
Experience of Students Nurses regarding Caring of Mothers' Undergone Caesarean Section at Postnatal Ward at Katutura State Hospital
}

\author{
Fransina Ndapewa Shikalepo, Hans Justus Amukugo
}

Department of General Nursing Health Science, School of Nursing, Faculty of Health Sciences, University of Namibia, Windhoek, Namibia

Email: hamukugo@unam.na

How to cite this paper: Shikalepo, F.N. and Amukugo, H.J. (2018) Experience of Students Nurses regarding Caring of Mothers' Undergone Caesarean Section at Postnatal Ward at Katutura State Hospital. Open Access Library Journal, 5: e4403. https://doi.org/10.4236/oalib.1104403

Received: February 3, 2018

Accepted: March 24, 2018

Published: March 27, 2018

Copyright $\odot 2018$ by authors and Open Access Library Inc.

This work is licensed under the Creative Commons Attribution International License (CC BY 4.0).

http://creativecommons.org/licenses/by/4.0/

c) (i) Open Access

\begin{abstract}
The purpose of this study was to explore and describe the experiences of second year University of Namibia nursing students regarding caring of mothers' undergone caesarean section at postnatal ward at Katutura state hospital. Participants were purposively sampled and unstructured individual interviews were used to collect the data amongst eleven students. This was done after permission was granted by the Ministry of Health and Social Services and from the University of Namibia. Informed consent was obtained and the researcher ensured the ethical principle of justice, autonomy, beneficence and respect. Data was analysed using TESCH'S method of data analysis that merged to the formation of five (5) themes and eight (8) subthemes. The results indicated that participants experience challenges during the care of mother's undergone caesarean section. Participants expressed patient factors that are hindering the caring of mothers. Participants also expressed different experiences regarding learning opportunities and different emotions regarding caring of mother's undergone caesarean section. Recommendations were made regarding reinforcement of guidelines and policies which govern health care personnel and introduction of new policies which will promote the health and wellbeing of mothers who have undergone caesarean section, and also improve health education on wound care and aseptic techniques within service training programs.
\end{abstract}

\section{Subject Areas}

Gynecology \& Obstetrics, Nursing

\section{Keywords}

Experience, Nursing, Students, Caring, Caesarean Section, Hospital 


\section{Introduction and Background}

A caesarean section (C/S) is an operation in which the baby is delivered through incisions made in the mother's abdomen and uterus [1]. A caesarean birth is recommended when a normal vaginal delivery is impossible or difficult and would put the wellbeing of the mother or the baby at risk [2]. Caesarean section indications include: placenta praevia, cephalopelvic disproportion, fetal distress, presentation of the baby and prolapsed cord [3]. Before the incision is made, the skin is prepared to reduce wound infection in the operating room by applying a surgical solution, and hair is removed from the operative site with a razor [4].

There are different types of caesarean sections. A lower segment caesarean section is the most common type, because it causes less bleeding, which means less chances of blood transfusion [5]. A classical caesarean section is another type rarely performed, because it has a higher rate of uterine rupture. Women undergoing caesarean section are at risk for multiple intraoperative complications, including excessive bleeding, injury to adjacent organs such as the bladder, bowel, gastrointestinal tract and maternal death [4]. Women who undergo a caesarean section often have a wound which requires monitoring and care. A study regarding caesarean section wound care and pain relief [6] revealed that removing the dressing after the first 24 hours postoperative had multiple advantages: wounds can be easily observed for primary signs of complications and personal hygiene is easier to carry out without a wound dressing. Caesarean section rates continue to bring worldwide concern because of their fast increase [7]. Caesarean deliveries were mainly carried out to separate the mother and the foetus in an attempt to save the foetus of a mother at a dying point [8]. This operation then became a surgical procedure to resolve both maternal and fetal complications, which cannot be resolved by vaginal delivery [9].

According to a study regarding the increasing trend in Caesarean section rates: Global, Regional and National Estimates: 1990-2014, [7] revealed that currently $18.6 \%$ of all births occur by caesarean section. Between 1990 and 2014, the global average caesarean section rate increased with an average annual rate of increase of $4.4 \%$. The lowest rate was found in Africa specifically in western Africa followed by Asia, Europe, Oceania, and North America, with Latin America and the Caribbean having the rates at $40.5 \%$. South America is the sub region with the highest average of caesarean section rates in the world [7]. According to [10], the followings are some of points regarding maternal WHO: improving the availability, accessibility, quality and use of services for the management and treatment of complications of pregnancy, labour and delivery. As such, the WHO has defined a concept of emergency obstetric care services "EmOC" which requires, for a basic level of services, that an institution will be able to provide intravenous antibiotics, utero tonic drugs, and intravenous magnesium sulphate and have the health care workers who remove a placenta manually [10].

\section{Problem Statement}

According to WHO (2015) caesarean section can cause critical and sometimes 
chronic complications, disability or death particular in settings that lack the facilities and capacity to properly render care to mothers undergone this surgical procedure and treat surgical complications. For many women child birth is exciting, joyous and empowering experience. For others it can be one of the most traumatic events of their lives. Memories of childbirth can vivid, deeply felt, and last many years perhaps a lifetime. For some it is quite an experience that leaves them feeling distressed, confused, and angry [1]. Students are the main concern when it comes to the care of mothers, mainly because they are inexperienced and not competent with the aseptic technique and psychological care of the mother, therefore it is important to study the experience of students regarding care of mothers' undergone caesarean section at postnatal ward at Katutura State hospital.

\section{Purpose and Objectives}

The purpose of this study was to explore and describe the experiences of second year University of Namibia nursing students regarding caring of mothers' undergone a caesarean section at postnatal ward at Katutura State Hospital. While the objectives of this study were to explore the experiences of second Year University of Namibia nursing students regarding caring of mothers' undergone a caesarean section at postnatal ward at Katutura State Hospital and describe the experiences of second year University of Namibia nursing students regarding caring of mothers' undergone a caesarean section at postnatal ward at Katutura State Hospital.

\section{Methodology}

A qualitative, explorative, descriptive, and contextual approach was employed to explore and describe the experience of second year UNAM nursing students regarding caring of mothers' undergone caesarean section at postnatal ward at Katutura state hospital. A qualitative design represents an attempt to understand people's interpretation in this study, the students who have cared for mothers undergone a caesarean section at postnatal ward at Katutura state hospital [11]. Equally the study was contextual; a contextual design provides an understanding of users or human to find out their fundamental intents, desires, and drivers [12]. The target population for this study were all the second year UNAM nursing students allocated at postnatal ward at Katutura state Hospital during the data collection period.

The estimated total population of second year nursing degree students is $(\mathrm{N}=$ 80). Unstructured individual interviews among eleven students were used and the sample was determined by the saturation of data. A purposive sampling method was utilized for this study. The inclusion criteria included, second year UNAM nursing degree students who registered for midwifery two in the year 2017, who have worked at postnatal ward Katutura State Hospital and agreed to participate voluntary and has interest to provide input into research process. The 
exclusion criteria excluded, nursing students who were not second year at UNAM. Nursing students who did not care for a patient under gone a caesarean section at least two to three times and second year UNAM nursing students who were not registered for midwifery two. The pilot study was conducted among (3) three second year students at the University of Namibia. Those participants were excluded from the actual research. Detected problems were used to determine whether the recommended study is feasible, refine research instruments, and diagnose problems with the design of the study. Data was collected at Katutura state Hospital at the postnatal ward. Unstructured individual interview, tape recorders and field notes were used to collect the data. The data was collected by the researchers, after introduced themselves prior to the interviews and explain the purpose of the research to the participants. All participants were asked one same question, the interviewer started with a broad opening question "tell me about your experience regarding caring of mother undergone caesarean section?" The interviewer invited participants to give more information or explain themselves further by probe follow up's.

The interviews were voice recorded with the permission of the participants to ensure precise transcripts. Consent obtained from the participants included the purpose and objectives of the research study, methods and duration. The demographic data that were discussed were gender, age and educational level. Respondents were $(\mathrm{N}=11)$ in the study, 5 that is $(45 \%)$ were males and 6 that is (55\%) were females. Age for all respondents out of 11 participants, 5 that is (46\%) were between the ages of 19 to 22,4 that is (36\%) were between the ages of 23 to 25 while 2 that is (18\%) were between the ages of 26 to 30.8 that is $(73 \%)$ of the participants had primary and secondary education while 3 that is $(27 \%)$ of the participants had primary, secondary and tertiary education.

The researchers adopted strategies suggested by Lincoln and Guba as cited by Tappen [13] to establish trustworthiness of the data. These strategies describe trustworthiness as the degree of confidence that the qualitative researcher have in their data by using the criteria of credibility, transferability, dependability and conformability. In this study, credibility was maintained through prolonged engagement, persistent observation, triangulation, referential adequacy, peer group debriefing, and member checking Staying in the field until data has been saturated, this enabled the researcher to gain trust from the participants by establishing rapport with them [15]. Close rapport with participants provided access to richer information this was done to ensure the criteria of prolonged engagement. The researcher solicited participants' views on the credibility of the findings and interpretations by replaying the tape to ensure the criteria of member checking. Persistent observation was ensured by consistently pursuing interpretations in various ways and look for multiple influences. Referral adequacy as criteria of credibility was ensured by determining that all materials needed to document findings are available.

The researcher ensured transferability by dense description and purposive 
sampling [16]. The researcher ensured transferability by providing sufficient (thick) descriptive data in the research report for consumers to evaluate the applicability of the data to other contexts, to ensure the criteria of dense description. A purposive sampling method was employed in order to deliberately select the participants who will be able to give rich information about their experiences of caring for mothers' undergone caesarean section at postnatal ward at Katutura state hospital, this method was employed to ensure the criteria of purposive sampling.

Dependability refers to the stability (reliability) of data over time and the conditions [17]. Dependability was ensured through audit, triangulation and peer examination [18]. The criterion of audit was ensured by Research methodology and questions contained in the interview guide were checked by the study supervisors for relevance before the actual data collection [19]. The researcher was guided by the study supervisors to ensure compliance with the institution's protocols. The study's methodology was described in detail and a literature review was conducted during the study.

Individual interviews, field notes and a voice recorder were used as methods of data collection. The researcher compared the notes with the recordings. Qualitative, explorative and descriptive designs were used in compliance with the criteria of triangulation. Research experts were involved to give opinions on the study to ensure the criteria of peer examination. Sample and sampling procedures, data collection and analysis were described in the study. And complete comprehensive transcriptions of the interviews were created, to ensure the criteria of dense description. To ensure coding, the researcher analysed the data after which themes and sub-themes for the study were identified. The application of conformability was ensured with the criteria of conformability audit, a literature was conducted for this study.

The data about students experience was recorded with a tape recorder as mentioned in data collection procedure, these data was: translated, transcribed, coded, that merged to the formation of five (5) themes and eight (8) subthemes. Data was analysed using TESCH'S method of data analysis.

The researcher collected data during the month of September 2017, Permission to conduct research was granted from relevant authorities such as Ministry of Health and Social Services and the University of Namibia. Informed consent was written and explained to the respondents. Ethical principles were maintained that is principle of respect, participants were allowed to voluntary participate in the research study without any risk of penalty or prejudicial treatment [20]. Principle of anonymity was ensured, participants were not asked their name, and they were allocated numbers in order to identify them. To ensure the principle of beneficence, participants had the right to protection and no harm at all [21]. The principle of confidentiality and justice was ensured by right to fair selection and treatment in the research study. Privacy of the participants was ensured by making sure that no one else has access to collected data except for the researcher. 


\section{Results}

The results were discussed according to the (5) five themes and (8) subthemes (Table 1).

Theme 1: Participants experience challenges during the care of mothers undergone a caesarean section.

Challenges refer to something which is new and difficult and requires great effort determination. In this study participant experienced challenges during the care of mothers underwent a caesarean section. Two subthemes will be discussed under this theme.

Sub-theme: Lack of medical equipment

Medical equipment refers to equipments used for the specific purposes of diagnosis and treatment of disease or rehabilitation following disease or injury, which can be used either alone or in combination with any accessory, consumable or other piece of medical equipment. Medical equipments are such as patient bed, bedpans, blood transfusion sets, and infection control equipments such as gloves. In these study participants experienced lack of medical equipments which was a challenge during caring of mothers undergone caesarean section. The following is the direct quote of participants regarding lack of medical equipment:

"In most cases when we have to do patient's vital signs we have to run round to block $B$ or maternity ward just to get even a $H B$ meter or the blood pressure machines, thermometers are not functioning and there are few in the ward." P\#10

Another participant mentioned that:

"Antibiotic medications are not always available and cottons the cottons we are using here are not sterile because there is no sterile ones aaahhh!! We have to use normal ones which sometimes introduce infection to the wound." P\#5

Sub-theme: Language barrier

Table 1. Themes and sub-themes of participants' experience.

\begin{tabular}{ll}
\hline \multicolumn{1}{c}{ Themes } & \multicolumn{1}{c}{ Subthemes } \\
$\begin{array}{l}\text { Theme 1: Participants experience challenges during } \\
\text { the care of mothers undergone a caesarean section }\end{array}$ & - $\quad$ Lack of medical equipment \\
$\begin{array}{l}\text { Theme 2: Participants expressed patient factors that } \\
\text { are hindering the caring of mothers }\end{array}$ & Patients don't take medication as prescribed. \\
$\begin{array}{l}\text { Theme 3: Participants expressed different } \\
\text { experiences regarding learning opportunities. }\end{array}$ \\
$\begin{array}{l}\text { Theme 4: Participants experienced different } \\
\text { emotions regarding caring of mothers undergone a } \\
\text { caesarean section }\end{array}$ \\
$\begin{array}{l}\text { - } \\
\text { Theme 5: Participants recommending some } \\
\text { strategies in caring of mothers after caesarean section }\end{array}$
\end{tabular}


Language is the key to any person's self-identity which enables the person to express their emotions, share feelings, tell stories and convey complex messages and knowledge. Language is a great mediator and promotes effective communication among people that provide a significant frame of reference relational context that sustains people's identity. It can be defined as a figurative phrase used primarily to refer to linguistic barriers to communication, the difficulties in communication experienced by people or groups speaking different languages. Participants experienced language barrier as a challenge during the care of mothers' undergone caesarean section.

The following was a response from one participant:

"I think uhhmm!! It is hard for some of us students who speak for example Damara and assisting an Oshiwambo or Okavango speaking woman because most of them don't understand English they don't really get a consent of what we are doing to them there are often no translators and it limits the care you want to provide and uhm!! It makes me feel guilty doing something to a mother while she does not understand what I am doing" P\#1

Another participant said:

"Some information is very hard especially medical terms to put in another person's vernacular language most Doctors expect us to translate what they've said to mothers but it is very hum ... confusing (laughter)." $P \# 11$

Theme 2: Participants expressed patient factors that are hindering the caring of patients.

In this theme participants expressed some of the patient factors that are hindering the caring of patients undergone a caesarean section. According to Merriam Webster's dictionary a factor is a circumstance, fact, or influence that contributes to a result. In this study participants expressed patient factors that are hindering the caring of patients such patients not taking medications as prescribed [22].

Sub-theme: Patients don't take medication as prescribed.

Medication refers to the legal use of drugs to cure or treat an illness; medicine is the science and practice of the diagnosis, treatment and prevention of disease. Medicine contains a variety of health care evolved to maintain and restore health by the prevention and treatment of illness. According to participants patients on discharge get their medication to take home some patients do not take their medication as prescribed which leads to mothers getting unnecessary re admissions, illness and sometimes even death. The following statement was narrated by one of the participants during the interview:

"When caring for patients that have gone through a caesarean section I think it is complicated because mothers don't take their medication like we tell them to on discharge they do not adhere to medication some take medications on an empty stomach some take a lower dosage than what they are told to and some even forget to take the medicine and forget to come back for follow up dates as well." $P \# 3$ 
Another participant responded that:

"For instance you tell the mothers hmm ... not to drink the Oshiwambo Traditional brew called oshikundu the first days after delivery because it gets fermented this traditional brew has a bad interaction with medicine and it can rupture the wound." $P \# 6$

Theme 3: Participants expressed different experiences regarding learning opportunities.

Participants acknowledged that they got a great opportunity to learn especially what they are not taught in class, and to practise what they have learned, they learned how to manage various conditions and how to monitor the mother's condition after undergoing a caesarean section. Learning opportunities are defined as the key to ensuring that you retain new knowledge and skills and apply them when you get back to work or tell others about it [23]. In this study participants expressed different experiences regarding learning opportunities.

Sub-theme: Management of post-partum haemorrhage

Post-partum haemorrhage is excessive vaginal bleeding after deliver until 42 days post-partum, it can be classified as primary post-partum bleeding, if within 24 hours of delivery, and secondary post-partum bleeding, if after 24 hours but within 42 days of delivery. To this the participants said that:

"I learned that a mother has to loose $500 \mathrm{ml}$ of blood after delivery from the genital tract for it to be classified as post-partum haemorrhage." P\#8

A common response given by one of the participants:

"When a woman has lost too much blood you first shout for help hmm!! Like I am going to do it now (clearing her throat well) ... help!!! PPH!!! And you inform one of the nurses to call a doctor immediately while you rub the uterus or put the baby to the breast can also help to lower the blood flow." P\#7.

Sub-theme: Monitor vital signs and detect abnormalities

Monitor refers to observe and check the progress or quality of something over a period of time, keep under systematic view. Vital signs are a group of the most important signs that indicate the status of the body's life sustaining functions these measurements are taken to show progress toward recovery, there are different types of vital signs such as pulse rate, respiration rate, blood pressure and temperature. Detection of abnormalities refers to the action or process of identifying the presence of something which is deviating from what is normal or usual. The following is the direct quotes of participants:

"I saw how they care for mothers how to give proper attention like uhhmm!!! monitoring vital signs and detect abnormalities such as elevated temperatures that can indicate ahh ... a sign of infection even me personally you never know one day at home I will be able to give necessary care to someone who had a caesarean section alone with no one's help." P\#2

Another participant mentioned that:

"I learned a lot but at first it was challenging Uhm like when we had to extract some blood clots that remained in the birth canal it was a huge Uhm!! Learning step for me." P\#5 
Theme 4: Participants experienced different emotions regarding caring of mothers had undergone a caesarean section.

Emotion is defined as the affective aspect of consciousness, a conscious mental reaction such as anger or fear is subjectively experienced as strong feeling usually directed toward a specific object and typically accompanied by physiological and behavioural changes in the body [22]. The above mentioned emotions are described below.

Sub-theme: Anxiety

Anxiety is a general term for several disorders that causes nervousness, fear, apprehension and worrying. Anxiety affects how we feel and behave and they can manifest real physical symptoms such as shivering, people experience a general state of worry or fear before confronting something challenging such as a test examination or interview. The following are the direct quotes of participants:

"My first experience ... It was quite challenging I was doubting myself whether this mother is really safe to be under my care I was not competent at all I was shivering and sweating I kept looking at ... the registered nurse I could not even hold the artery forceps correctly to remove stitches because my hands were shaking non-stop (laughing).” P\#4

Another participant said that:

"Every time I had to empty a mother's catheter my heart was beating so fast as if I had butterflies in my stomach I was scared like what if I pull out this catheter and putting the port vac drain in position I didn't even want to touch it hmm ... I had thoughts like what if this blood spills on me." $P \# 8$

Theme 5: Participants recommending some strategies in caring of mothers after caesarean section.

A recommendation refers to a suggestion or proposal as to the best course of action, especially one put forward by an authoritive body [24]. Strategy refers to a method or plan chosen to bring about a desired future, such as achievement of a goal or solution to a problem. A strategy describes how the goals will be achieved by the resources [25]. In this study participants recommended some strategies in caring for mothers undergone a caesarean section. The above mentioned strategies are recommended below.

Sub-theme: health education on wound care, breastfeeding and aseptic techniques.

Health education is any combination of learning experiences designed to help individuals and communities improve their health, by increasing their knowledge or influencing attitudes.

The following statement was narrated by one of the participants during the interview:

"Haa!!Okehaa!! I think the nurses should give enough health education as required within their scope of practise to the mothers so that they can understand the importance of wound care so they can come back of follow-up on time to prevent implications that can happen if their dressing is not done as required." 
P\# 3

One participant also mentioned that:

"I feel like mothers need more health education on how to breast feed and correct attachment of the baby on the breast. Some mothers can't even hold their own babies it's a pity, so they have to force the baby to take in milk and they usually don't have strength because they are in pain." P\#11

Sub-theme: Recommend guidelines and policies on caesarean section.

The term guide line refers to a general rule, principle, or piece of advice. A policy refers to a course or principle of action adopted or proposed by an organization or individual. The following are the responses from participants regarding recommendation of guidelines and policies on caesarean section:

"I think the first thing that that should be done is they should reinforce the policies uhhhmm!! Which govern or which the health personnel are working under they should be reinforced and they should not allow them to be broken by anyone." P\#5

Another participant also stated that:

"I think ahh ... (Smiling) the government should introduce new guidelines which will uhmmm! Promote the health and wellbeing of the mothers who have gone through a caesarean section and improve quality of care." P\#7

\section{Discussion}

The aim of this study was to explore and describe the experience of second year UNAM nursing students regarding caring of mother's undergone caesarean section at postnatal ward at Katutura state hospital. The main themes and subthemes that emerged from the analysis of data from the interviews are summarized below.

Theme 1: Participants experience challenges during the care of mothers undergone a caesarean section, Challenges refers to something which is new and difficult and requires great effort determination. Under this two sub themes were discussed, lack of medical equipment and language barrier were great challenges experienced by participants. The findings are in line with a study conducted by WHO, in Gaza regarding medical equipment, which revealed that lack of medical equipment brings high economic and human costs, hospitals cannot run efficiently using equipment that is faulty, unreliable or that is out of service [10]. Another study conducted by Adams \& Rother in South Africa regarding language barrier revealed that language barrier compromises patient quality of care from the nurses, where those who cannot communicate with health care providers are less likely to adhere to treatment. These challenges influence health care deliver, their motivation and job satisfaction [26].

Theme 2: Participants expressed patient factors that are hindering the caring of mothers. There are different factors that are hindering the caring of mother's undergone caesarean section, such as such as patients not taking their medication as prescribed. Participants mentioned that most of complications such as 
readmission, illness and death are brought upon by mothers themselves. Findings are in line with a study conducted by Brown, Bussell, regarding Medication Adherence, WHO cares? Revealed that, measurement of medication adherence is an individual patient behaviour. Lack of adherence is the most important cause of failure to achieve optimal wellbeing [27].

Theme 3: Participants expressed different experiences regarding learning opportunities. Participants stated that they have learned how to manage and diagnose various conditions and are now competent in doing so. They learned how to manage and diagnose post-partum haemorrhage which is described as the excessive vaginal bleeding after deliver until 42 days post-partum. Participants also mentioned that they learned how to monitor vital signs and detect abnormalities. These findings are line with a study conducted by Bambini, Washburn \& Perkins, regarding Clinical simulation for Novice Nursing students: Communication, Confidence, Clinical judgement which reveals that the use of clinical practise provides many opportunities for students to learn which increased their level of confidence in providing care to a mother who had a caesarean section [28]. The same study conducted by Bambini, Washburn \& Perkins also revealed that students experienced an increase in confidence in assessing vital signs, breasts, the fundus and abnormalities [28].

Theme 4: Participants expressed different emotions regarding caring of mothers undergone a caesarean section. Under this a subtheme was described which is experience of anxiety among participants was mentioned causing fear, apprehension and worrying. Participants' experienced mixed emotions regarding the care of mothers had undergone a caesarean section. These study's findings are line with a study conducted by Leeuwen, Oosterhuis \& Ruyter, regarding Anxiety and categorisation effects in student nurses' attitudes towards young and older patients: A dual pathway model also revealed that anxiety is harmful to some students; it is associated with high levels of worry that can affect performance [29].

Theme 5: Participants recommended some strategies in caring of mothers after caesarean section, these are the recommendations given by nursing students regarding the improvement of caring for mothers undergone a caesarean section. Most participants mentioned: health education on wound care, breastfeeding and aseptic techniques needs to be improved, guidelines and policies on caesarean section should be reinforced and for new policies and guidelines to be introduced. These study's findings are in line with a study conducted by Glanz, Lewis \& Rimer regarding the importance of healthcare education in wound healing, revealed that health education improves individual health as well as enhance the performance of health care industry [30].

\section{Limitation}

The study was conducted among second year UNAM nursing students who have cared for mothers undergone a caesarean section at postnatal ward at Katutura State Hospital. It was conducted among a small number of students, therefore 
the study's results cannot be generalised to the broader population because the participant's geographical and cultural orientation may not be the same as that of students in other regions. This study was conducted through individual interview. Some of the students were not able to participate, which means in-depth information could not be obtained.

\section{Conclusion}

This study explored and described the experience of students regarding caring of mothers' undergone caesarean section at postnatal ward at Katutura state hospital. This study finding showed that participants experienced great challenges during the caring of mothers' undergone caesarean section. Participants revealed that participants learned a lot on how to manage various conditions associated with caesarean section. Participants also revealed they've experienced different emotions regarding the caring of mothers' undergone caesarean section and made some recommendations regarding the caring of mothers' undergone caesarean section.

\section{Recommendation}

The recommendations were made based on health education, managerial and related research aspects.

Health education: It is critically important to improve and scale up health education among mothers and among health care providers. A health education program about wound care and aseptic techniques after caesarean section can be introduced. Such a program can create awareness and knowledge amongst health care providers and student nurses from all training institutions. This knowledge can be utilised to influence mothers positively with regard to taking care of themselves after undergoing caesarean section. Health education programs in the postnatal wards in languages that mothers can understand about correct breastfeeding positions that will not cause the mother much pain after undergoing caesarean section should be introduced.

Recommendation for guidelines and policies on caesarean section management: It is recommended that the MOHSS, in collaboration with nursing training institutions develops in-service trainings with well stipulated learning outcomes about infection control on wound dressings, to prevent and reduce septic wound cases. It is also recommended that the postnatal ward at Katutura State hospital management reinforce guidelines and policies which govern health care personnel and encourage health personnels to practise existing policies which will promote the health and wellbeing of mothers who have undergone caesarean section.

Future research: The researcher proposes the following supplementary research focus, to explore the experiences of registered nurses regarding caring of mother's undergone caesarean section at postnatal ward at Katutura state hospital and future studies should apply a quantitative research method to make effective comparisons. 


\section{References}

[1] World Health Organization, WHO. (2015) Caesarean Section Should Only Be Performed When Medically Necessary. Research of the WHO, Geneva.

[2] Fenlon, A., Oakes, E. and Dorchak, L. (1986) Getting Ready for Child Birth. 3rd Edition, Little, Brown and Company Limited, Canada, United States of America.

[3] Yeniel, A.O. and Petri, E. (2014) Pregnancy, Childbirth, and Sexual Function: Perceptions and Facts. International Urogynecology Journal, 25, 5-14. https://doi.org/10.1007/s00192-013-2118-7

[4] Galan, H., Goetzl, L., Landon, A. and Jauniaux, E. (2007) Obstetrics Normal and Problem Pregnancies. 5th Edition, Churchill Livingstone Elsevier Inc., China.

[5] Slade, R., Laird. and Beynon, G. (1993) Key Topics in Obstetrics and Gynaecology. BIOS Scientific Publishers Limited, United Kingdom.

[6] Bick, D., MacArthur, C., Knowels, H. and Winter. (2002) Postnatal Care Evidence and Guidelines for Management. 4th Edition, Elsevier Limited, United Kingdom.

[7] Zeeb, H. (2016) The Increasing Trend in Caesarean Section Rates: Global, Regional and National Estimates. PLOS ONE, 11, e0148343.

[8] Gizzo, S., Andrisani, A., Noventa, M., Di Gangi, S., Quaranta, M. and Cosmi, E. (2015) Caesarean Section: Could Different Transverse Abdominal Incision Techniques Influence Postpartum Pain and Subsequent Quality of Life? A Systematic Review. PLoS ONE, 10, e0114190. https://doi.org/10.1371/journal.pone.0114190

[9] Placek, P.J. and Taffel, S.M. (2016) Recent Patterns in Caesarean Delivery in the United States. Obstetrics \& Gynecology Clinics of North America, 15, 607-627.

[10] World Health Organization. (2009) WHO Handbook for Monitoring Emergency Obstetric Care. Geneva, Switzerland.

[11] Burns, N. and Groves, S.K. (2009) The Practice of Nursing Research: Appraisal, Synthesis and Generation of Evidence. 6th Edition, Saunders Elsevier, United States of America.

[12] Davies, T.T., Kumtepe E.G. and Aydenis, M. (2007) Fostering Continuous Improvement and Learning through Peer Assessment: Part of an Integral Model Assessment. Educational Assessment, 12, 112-135.

[13] Guba, E.G. and Lincoln, Y.S. (2005) Naturalistic Inquiry. Sage, London.

[14] Polit, D.F. and Hungler, B.P. (2006) Nursing Research Principles and Methods. Lippincott, Philadelphia, PA.

[15] Du Plooy-Cilliers, F., Davis, C. and Bezuidenhout, R. (2014) Research Matters. Paarl Media Paarl, South Africa.

[16] Creswell, J.W. (2008) Educational Research: Planning, Conducting and Evaluating Qualitative \& Quantitative Research. Pearson Education, London.

[17] Polit, D.F. and Beck, C.T. (2012) Nursing Research: Generating and Assessing Evidence for Nursing Practice. 9th Edition, Lippincott William \& Wilkins, Philadelphia.

[18] Lindolf, T.R. and Taylor, B.C. (2002) Qualitative Communication Research Methods. 2nd Edition, Sage Publications, Thousand Oaks.

[19] Brink, H., Van de Walt, C. and Van Rensburg, G. (2012) Fundamentals of Research Methodology for Healthcare Professionals. Juda and Co. Ltd., Cape Town.

[20] Matheson, J.L. (2007) The Voice Transcription Technique: Use of Voice Recognition Software to Transcribe Digital Interview Data in Qualitative Research. The 
Qualitative Report, 12, 547-560.

[21] Munhall, I.L. (2001) Basics in Research Methods.

[22] Merriam-Webster Collegiate Dictionary (2004) New Ways to Find the Words You Need. 11th Edition, an Encyclopedia Britannica Company.

[23] Given, L.M. and Saumure, K. (2008) The SAGE Encyclopedia of Qualitative Research Methods. https://doi.org/10.4135/9781412963909

[24] (2006) Oxford Advanced Learner's Dictionary of Current English. 4th Edition, Oxford University Press, Oxford.

[25] Freedman, L. (2015) Strategy: A History. Oxford University Press, Oxford.

[26] Adams, J. and Rother, H. (2017) A Qualitative Study of Language Barriers between South African Health Care Providers and Cross-Sectional Boarder Migrants. BMC Health Services Research, 27, 17-19.

[27] Brown, R. and Bussell, T. (2011) Medication Adherence WHO Care? Master's Thesis, Rush University, Chicago.

https://www.ncbi.nlm.nih.gov/pmc/articles/PMC3068890/

[28] Bambini, D., Washburn, J. and Perkins, R. (2009) Outcomes of Clinical Simulation Novice Nursing Students: Communication, Confidence, Clinical Judgement. International Journal for Health Care Education, 30, 79-82. https://www.ncbi.nlm.nih.gov/pubmed/19476069

[29] Leeuwen, E., Osterhuis, M. and Ruyter, S. (2016) Anxiety and Categorization Effects in Student Nurses' Attitudes towards Young and Older Patients: A Dual Pathway Model. University of Leiden, Leiden.

http://www.nurseeducationtoday.com/article/S0260-6917(16)00050-2/abstract

[30] Glanz, K., Rimer, B.K. and Viswanath, K. (2008) Health Behavior and Health Education: Theory, Research, and Practice. 4th Edition, Jossey-Bass, San Francisco. 